\title{
Osteocalcin Level and its Association with Vitamin D Receptor Gene Polymorphisms (TaqI and ApaI) in Iraqi Obese Type 2 Diabetes Mellitus
}

\author{
Reema M. Abed \\ Department of biotechnology/College of Science / Baghdad University / Iraq \\ Email: reema.aloubaidy[at]yahoo.com
}

\begin{abstract}
In order to explore the association of serum 25-hydroxy vitamin D concentration and it is gene receptor polymorphisms with Osteocalcin state for Iraqi obese type 2 diabetes mellitus individuals. Genomic DNA was obtained from leucocytes by using a standard salting out process. The polymorphisms had been genotyped by PCR -RFLP technique by using certain primers. ELISA was used to evaluate Insulin and Osteocalcin along with other biochemical parameters concentration. A significant reduction in Osteocalcin concentration within obese type 2 diabetes mellitus Iraqi individuals in comparability with the healthy obese non diabetic control group. The reduction depends on a number of elements, like period of disease and age individuals, aside from that to BMI. Mean serum Osteocalcin proved excellent correlations with intact parathyroid hormone $(P T H)(r=0.471, P<0.01)$ in the entire public of all of type 2 diabetes mellitus Iraqi individuals. However mean serum Osteocalcin concentration was adversely correlated with serum high sensitivity $C$ reactive protein (hs $C R P)$ among the type 2 diabetes mellitus Iraqi cases $(r=-0.56, P<0.01)$ and with serum vitamin $D$ concentration $(r=-0.52, P<0.01)$, weight $(r=-0.48, P<0.01), B M I(r=-0.63, P<0.01)$ in the all public of type 2 diabetes mellitus. Elevated levels of mean serum hs- CRP as well as lesser vitamin D have been related to lesser serum Osteocalcin status. Serum Osteocalcin is positively connected with whole adiponectin levels, and atherosclerosis parameters in individuals with type 2 diabetes mellitus, suggesting that Osteocalcin is important for not only bone metabolism but also carbohydrate and lipid metabolism. In males, serum Osteocalcin negatively and significantly correlated with HbAlc, and FPG $(P<0.05, P<0.001)$. In females, serum Osteocalcin levels negatively and significantly correlated with HbAlc and FPG $(P<0.05$ as well as $P<0.001)$ and positively correlated with adiponectin $(P<0.001)$. The genotype TT of VDR gene at TaqI position demonstrated a significant $(P=0.045)$ increased percentage frequency in type 2 diabetes mellitus individuals (50 percent) when compared with control (thirty six percent), while the distribution of Tt genotypes was twenty three $\%$ in-individuals with type 2 diabetes mellitus incomparability to thirty \% in healthy subject. Alternatively the distribution of tt genotypes was reduced (twenty three \%) in individuals in comparability with thirty \% within healthy subject.
\end{abstract}

Keywords: Vitamin receptor, gene D polymorphism, Type 2 diabetes mellitus, Osteocalcin

\section{Introduction}

Osteocalcin is observed as one of the osteoblast specific proteins, has many hormonal characteristics, released within the common blood circulation from osteoblastic cells [1, 2]. Additional reports found that osteocalcin functions like a hormone which adjusts fat mass and glucose metabolism in genetically modified mouse display reduced insulin resistance, glucose intolerance, and betacell proliferation[3].Moreover, osteocalcin consumption controlled gene expression in adipocytes and betacells and also impacted the improvement of metabolic disease, obesity, as well as type 2 diabetes mellitus in wild type mice [4], accordance to experimental animal scientific studies; osteocalcin concentrations are proven to be reduced in-individuals with type 1 diabetes mellitus and type 2 diabetes mellitus [5]. On the other hands, it would seem there's adverse association between osteocalcin serum levels as well as glycosylated hemoglobin; together with better control diabetes, amounts of osteocalcin is going to be increase [6].Though, a few scientific studies are carried out that don't verify the association $[7,8]$.

The Vitamin D Receptor (VDR) gene encodes vitamin D receptor. Specific allelic versions in VDR are actually relevant to diabetes. VDR forms a heterodimeric together with the Retinoid X Receptor (RXR) that binds to the Vitamin D Receptor Element (VDRE) in the promoter region on the BGLAP gene to improve its transcription [9]. The coexistence on the TaqI T/C polymorphism and also the ApaI G/T polymorphism lead to marked linkage disequilibrium continues to be discussed. This might change one of many zinc fingers of nuclear signaling heterodimer which binds to VDRE DRE/VDR/RXR complex that be associated with an increased Osteocalcin basal transcription rate during osteoblast variation [10]. The Osteocalcin peptide is coded through the BGLAP gene [1]. A biological variant of Osteocalcin happens to be discussed to become a regulator of glucose metabolic rate in mice, while the expression of it's appears to be decreased in people with type 2 diabetes mellitus [3].Though inversely correlated with serum glucose levels, as well as glycated hemoglobin, it's not clear if this particular peptide under expression is brought on by diabetes or perhaps in case it plays a role in the pathogenesis and also advancement of the disease [11]. Since both VDR and Osteocalcin are in some way associated with the metabolic changes present in type 2 diabetes mellitus, it's reasonable to hypothesize that VDR polymorphisms can confer susceptibility to type 2 diabetes mellitus and also change the Osteocalcin levels. Although the results support the idea that bone metabolic process and glucose/fat metabolism are connected with one another via the activity of Osteocalcin, little is thought regarding whether serum Osteocalcin concentration is related with glucose, adiponectin, fat mass, or even in people underneath the impact of VDR gene polymorphisms. Therefore this particular analysis assessed the association between TaqI as well as ApaI VDR

\section{Volume 6 Issue 12, December 2017}




\section{International Journal of Science and Research (IJSR) \\ ISSN (Online): 2319-7064}

Index Copernicus Value (2016): 79.57 | Impact Factor (2015): 6.391

polymorphisms in relation to serum Osteocalcin status in individuals with type 2 diabetes mellitus [10].

\section{Materials and Methods}

\section{Individuals with type 2 diabetes mellitus and controls:}

A case- control analysis was enrolled on hundred individuals with type 2 diabetes mellitus (seventy females as well as thirty males) in comparison with hundred healthy controls (forty females as well as sixty males) in biotechnology department of the science college in Baghdad University. The analysis was accredited by, Ethics, Biosecurity, and the Research committee of the university, as well as written an informed consent was obtained from everyone in the group. Individuals which were enrolled had the next characteristics: type 2 diabetes mellitus individuals, not utilizing drugs for example insulin, oral contraceptives, coumarin, steroids, thiazides, thiazolidinediones, vitamin $\mathrm{K}$, vitamin $\mathrm{D}$, as well as calcium. The medical history of all of subjects within the analysis was gotten in addition to physical examination was performed. Height was calculated, as well as body composition was examined, blood samples have been collected after overnight fasting in dry tubes for biochemical evaluation of glucose, total cholesterol, triglycerides, HDLC, as well as VLDL- C using enzymatic colorimetric techniques (spinreackt, Spain); total osteocalcin and insulin, PTH and adiponectin had been assessed by ELISA strategy utilizing commercial kits from Abcam (USA).

\section{Ethical Statement}

All ethical principles have been respected in accordance with the resolution on the research involving human subjects. The ethics committee of Baghdad university of Medical Sciences authorized the analysis process and then supervised all of the stages.

\section{Genotyping}

Blood samples from all subjects had been collected overnight fasting in EDTA coated tubes for genotyping. Genomic DNA was obtained from peripheral blood samples utilizing promegakit (USA). TaqI SNP within exon nine as well as ApaI SNP within intron eight on the VDR gene had been analyzed by PCR- RFLP. The PCR for amplification of both polymorphisms was done with single pair primers created for the proximity between polymorphic sites.

The forward and reverse primer was: 5' 5'CCACCTCCCCTATCCACC3' respectively. PCR was carried out in fifty $\mu \mathrm{L}$ as final volume, containing $500 \mathrm{ng}$ of gDNA, $20 \mu \mathrm{M}$ of each primer forward and also reverse $1.5 \mathrm{U} / \mu \mathrm{L}$ Taq polymerase (Ferments, USA), $2.5 \mu \mathrm{L}$ of 10 $\mathrm{X}$ buffer, along with $2.5 \mathrm{mM}$ of each dNTP. The amplification was carried out during a programmable thermocycler as well as the fragments gotten had been examined on $1.8 \%$ agarose gel. However twenty $\mu \mathrm{L}$ of the amplified fragment were incubated with $3 \mathrm{U}$ ApaI restriction enzyme as well as twenty $\mu \mathrm{l}$ with $3 \mathrm{U}$ TaqI enzyme in a thermal bath according to the supplier's specification. PCR fragment and digestion products have been examined on $1.8 \%$ agarose gel stained with ethidium bromide (1\%).Genotyping was completed in duplicates, as well as designed conventionally by the first letter the name of the enzyme. A capital letter indicates the absence of the cut site, while a lowercase letter indicates the presence of its.

\section{Statistical analyses}

Genotype and allele frequencies of variations between groups have been analyzed utilizing Chi square test $\left(\mathrm{x}^{2}\right)$ as well as odd ratio (OR) with $95 \%$ confidence interval (MedCalc ${ }^{\text {TM }}$ Statistical Software). A student t test was for two group means comparisons, along with one way ANOVA was utilized to evaluate the clinical and laboratorial assessment based on each genotype. Logistic regression evaluation was carried out to assess associations between clinical and genetic parameters. Ages have been adjusted by using Kruskal-Wallis regression after which compared utilizing the Chi square test $\left(\mathrm{x}^{2}\right)$. Probability $(\mathrm{P})$ values $<0.05$ have been were considered significant. Statistical analyses had been carried out with SSPS 20 software (USA).

\section{Results}

\section{Patient Characteristics:}

Serum Osteocalcin proved excellent correlations with unchanged PTH $(\mathrm{r}=0.471, \mathrm{p}<0.0001)$ in the entire population of all diabetic type 2 individuals, on the other hands serum Osteocalcin was inversely correlated with serum high sensitivity C- reactive protein (hs- CRP) of all the cases $(\mathrm{r}=-0.283, \mathrm{p}<0.01)$ and was inversely correlated with serum vitamin $\mathrm{D}(\mathrm{r}=-0.165, \mathrm{p}<0.05)$, body weight $(r=-0.168, p<0.05)$, BMI $(r=-0.168, p<0.05)$ within the entire population of diabetics patients. Elevated levels of serum $C$ reactive protein and also vitamin $D$ have been related to lower serum Osteocalcin levels. Thus, Osteocalcin might be a possible cardiovascular risk marker. However, additional scientific studies are required to make clear the path physiological processes underlying the connection between serums Osteocalcin level as well as atherosclerosis parameters. Inverse correlations involving osteocalin and several obesity measures, specifically body weight, BMI, had been additionally noticed. Nevertheless, only body weight was discovered to get substantially correlated with serum osteocalcin separate from other potential confounders. Several regression evaluations modified for age range, period of diabetic and body mass index, demonstrated that Osteocalcin adversely correlated with fasting plasma glucose and HbA1c in both women and men $(\mathrm{P}<0.05)$. Osteocalcin positively correlated with complete adiponectin of females $(\mathrm{P}<0.001)$ also it's related with total adiponectin levels and glucose, body fat mass, along with atherosclerosis parameters in individuals with type 2 diabetes mellitus, suggesting that Osteocalcin is crucial for not merely bone metabolic rate but additionally as part of fat metabolism and glucose. In males, serum Osteocalcin

\section{Volume 6 Issue 12, December 2017}




\section{International Journal of Science and Research (IJSR) \\ ISSN (Online): 2319-7064}

Index Copernicus Value (2016): 79.57 | Impact Factor (2015): 6.391

significantly and negatively correlated with fasting glucose and $\mathrm{HbA1c}(\mathrm{P}<0.05, \mathrm{P}<0.001)$. In females, serum Osteocalcin levels significantly and negatively correlated with fasting glucose and $\mathrm{HbA1c}(\mathrm{P}<0.05$ as well as $\mathrm{P}<$ $0.001)$ and positively correlated with adiponectin $(\mathrm{P}<0.001)$.

Table 1: Baseline demographic and biochemical indices of control and type 2 diabetes mellitus cases

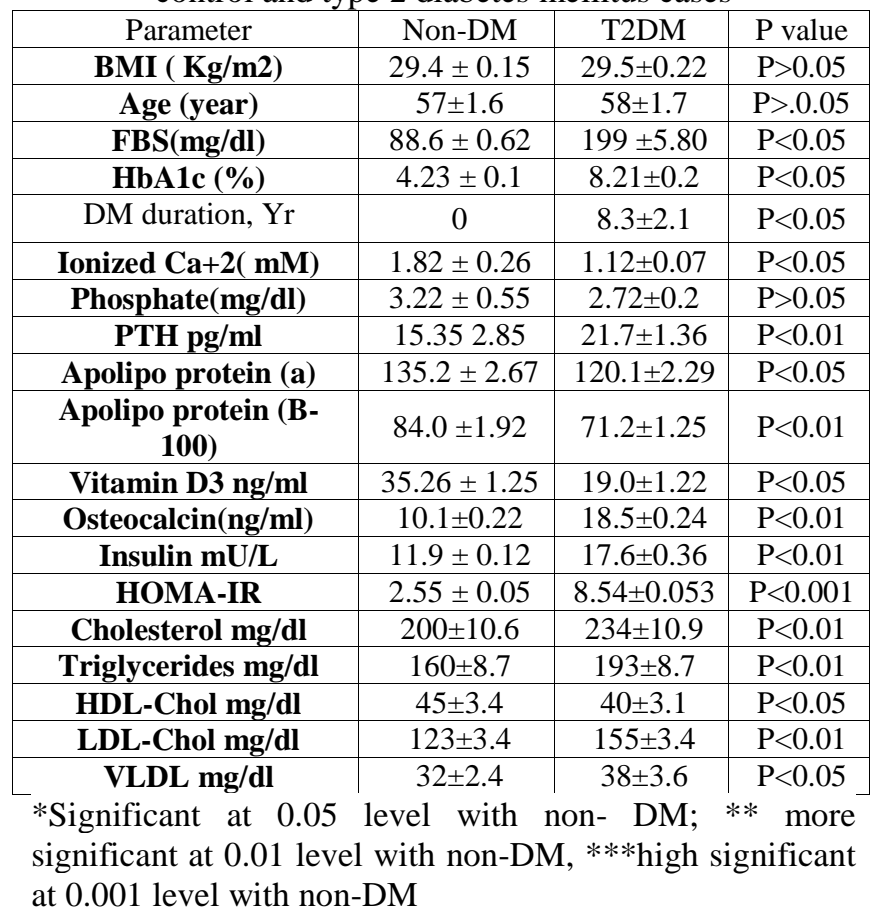

In conclusion, serum Osteocalcin levels have been discovered to associate with total adiponectin levels and glucose, along with body fat mass in addition to atherosclerosis parametersin individuals with diabetes. These results help support the latest idea which Osteocalcin is crucial for both bone and carbohydrate metabolic process and fat mass. In this particular evaluation of molecular genetics, data discovered that the homozygous TT genotype of TaqI was correlated with BMI and also serum osteocalcin levels. A significant correlation $(\mathrm{p}=0.025)$ between TT genotype of TaqI polymorphism was noticed only during obesetype 2 diabetes mellitus subject.

\section{PCR- RFLP genotyping of VDR gene:}

The consequences of PCR- RFLP analysis of the TaqI of the VDR gene for control and obese females are revealed in figure (1) and table (2) that are summarized when the wild type homozygote (TT), heterozygote (Tt) and Mutant homozygote (tt) confirmed 2 bands (495 and 205bp), 4 bands (495, 290, 245 and 205) bp, 3 bands (290, 245 as well as 205)bp respectively. The genetic polymorphism of VDR was determined at TaqIsite that had been offered with 3 genotypes (TT, Tt, tt for TaqI found type 2 diabetes mellitus individuals and controls. The genotype TT of VDR gene at Taq I position demonstrated a significant $(\mathrm{P}=0.045)$ increased percentage frequency in type 2 diabetes mellitus individuals (fifty percent) when compared with control (thirty six percent), while the distribution of $\mathrm{Tt}$ genotypes was twenty three \% in individuals with type 2 diabetes mellitus in comparability to thirty \% within healthy subject. On another hands the distribution of $t$ genotypes was reduced (twenty three \%) in individuals in comparability with thirty $\%$ in healthy subject. The difference was significant $(\mathrm{P}<0.05)$. The $\mathrm{T}$ and $t$ alleles have been similar in type 2 diabetes mellitus individuals and healthy subjects.

Figure (2) given the results of PCR- RFLP analysis at the ApaI of the VDR gene, There are 3 genotypes the wild type homozygote (AA), heterozygote(Aa) and also homozygote (aa) offer a one band (740) bp, 3 bands (740, $530,210)$ bp as well as 2 bands $(530,210)$ bp respectively. The genetic polymorphism of the VDR gene are provided in the ApaI site, with 3 genotypes (AA, Aa, aa) for ApaI in most type 2 diabetes mellitus individuals as well as subjects. Results exhibited the AA genotype frequencies had been much higher within obese type 2 diabetes mellitus individuals than the subjects (sixty \% vs. forty $\%$, $\mathrm{P}=0.005$ ) while Aa genotype frequencies were lower in the individuals compared to controls but the difference isn't significant (twenty four \% vs. thirty two \% respectively, $\mathrm{P}=0.2$ ). both $\mathrm{A}$ along with a alleles' frequency weren't significantly distinct between type 2 diabetes mellitus individuals when compared with the controls $(\mathrm{P}<0.05)$, and a allele frequency of type 2 diabetes mellitus individuals is forty eight $\%$ that had been the identical value within the control group, in addition a allele frequency is similar in type 2 diabetes mellitus individuals and control as revealed in table (3).

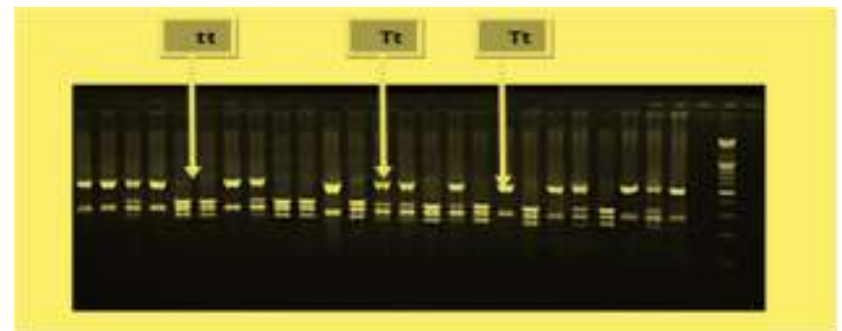

Figure 1: PCR- RFLP analysis of the VDR gene by the Taq1 in type 2 diabetes mellitus individuals and healthy subjects: The wild type homozygote (TT) showed 2 bands $(49,245) \mathrm{bp}$; heterozygote $(\mathrm{Tt})$ presented 4 bands $(495$, 290, 245, 205) bp Three bands $(290,245,205)$ bp were shown by Homozygote (tt). The product was electrophoresed on $1.8 \%$ agarose gel at 90 volt for one hour, stained with ethidium bromide, and then visualized under U.V light. (M=marker (100-2000bp)

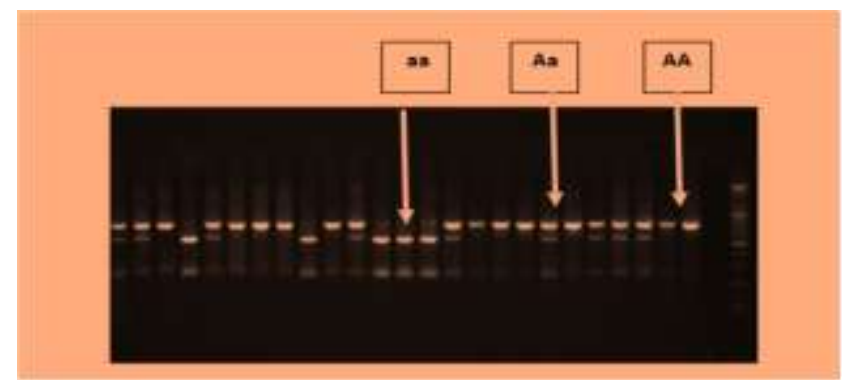

Figure 2: PCR- RFLP analysis of the VDR gene by the ApaI in the obesetype 2 diabetes mellitus individuals in addition to healthy subjects: The wild type homozygote (AA) confirmed one band (740)bp; heterozygote (Aa)

\section{Volume 6 Issue 12, December 2017}




\section{International Journal of Science and Research (IJSR) \\ ISSN (Online): 2319-7064}

Index Copernicus Value (2016): 79.57 | Impact Factor (2015): 6.391

proved 3 bands $(740,530,210)$, The product was electrophoresed on $1.8 \%$ agarose gel at 90 volt for one hour, stained with ethidium bromide, then visualized below U.V light source. M=marker (100-2000bp).

Table 2: Observed numbers and percentage frequencies wavelengths of VDR genotype and alleles at TaqI position in type 2 diabetes mellitus individuals and controls.

\begin{tabular}{|c|c|c|c|c|c|}
\hline \multirow[t]{2}{*}{$\begin{array}{l}\text { Genotype } \\
\text { or Allele }\end{array}$} & $\begin{array}{c}\text { type } 2 \\
\text { diabetes } \\
\text { mellitus } \\
(\text { No. }=100)\end{array}$ & $\begin{array}{l}\text { Controls } \\
(\text { No. }=100)\end{array}$ & \multirow[t]{2}{*}{$\mathrm{OR}^{*}$} & \multirow[t]{2}{*}{$95 \% \mathrm{Cl}$} & \multirow[t]{2}{*}{$\begin{array}{c}\mathrm{P}- \\
\text { value }\end{array}$} \\
\hline & $\%$ & $\%$ & & & \\
\hline TT & 39 & 20 & 2.55 & $\begin{array}{c}1.3578 \text { to } \\
4.8169 \\
\end{array}$ & 0.0034 \\
\hline $\mathrm{Tt}$ & 48 & 58 & 0.6374 & $\begin{array}{c}0.3726 \text { to } \\
1.0905\end{array}$ & 0.1002 \\
\hline $\mathrm{tt}$ & 13 & 22 & 0.5755 & $\begin{array}{c}0.2900 \text { to } \\
1.1421\end{array}$ & 0.1141 \\
\hline $\mathrm{T}$ & 63 & 49 & 1.7301 & $\begin{array}{c}1.1845 \text { to } \\
2.5271\end{array}$ & 0.0046 \\
\hline $\mathrm{t}$ & 37 & 51 & 0.5780 & $\begin{array}{c}0.3957 \text { to } \\
0.8443\end{array}$ & 0.0046 \\
\hline
\end{tabular}

*OR: Odd Ratio, 95\% CI: 95\% Confidence Intervals, p-value $<0.005$

Table 3: Observed numbers and percentage frequencies of VDR genotype and alleles at Apa I position in Obese type

2 diabetes mellitus patients and control

\begin{tabular}{|c|c|c|c|c|c|c|c|}
\hline \multirow{2}{*}{$\begin{array}{c}\text { Genotype } \\
\text { or Allele }\end{array}$} & \multicolumn{2}{|c|}{$\begin{array}{c}\text { type 2 } \\
\text { diabetes } \\
\text { mellitus (No.= } \\
\text { 100) }\end{array}$} & \multicolumn{2}{|c|}{$\begin{array}{c}\text { Control } \\
\text { (No.=100) }\end{array}$} & \multirow{2}{*}{ OR* } & \multirow{2}{*}{ 95\% Cl } & $\begin{array}{c}\text { P- } \\
\text { value }\end{array}$ \\
\cline { 2 - 6 } & No. & $\%$ & No. & $\%$ & & & \\
\hline AA & 60 & 60 & 40 & 40 & 2.25 & 1.27 to 396 & 0.005 \\
\hline Aa & 24 & 24 & 32 & 32 & 0.67 & $\begin{array}{c}0.36 \text { to } \\
1.254\end{array}$ & 0.20 \\
\hline aa & 16 & 16 & 28 & 28 & 0.52 & 0.26 to 1.05 & 0.07 \\
\hline A & 108 & 54 & 104 & 52 & 1.08 & $\begin{array}{c}0.730 \text { to } \\
1.961\end{array}$ & 0.683 \\
\hline a & 92 & 46 & 96 & 48 & 0.92 & $\begin{array}{c}0.624 \text { to } \\
1.2863\end{array}$ & 0.683 \\
\hline
\end{tabular}

*OR: Odd Ratio, 95\% CI: 95\% Confidence Intervals, p-value $<0.005$

Table 4: Vitamin D receptor genotypes and osteocalcin level intype 2 diabetes mellitus patients

\begin{tabular}{|c|c|c|c|}
\hline $\begin{array}{c}\text { Genotype } \\
\text { and allele }\end{array}$ & $\begin{array}{c}\text { type 2 diabetes } \\
\text { mellitus patients } \\
\mathbf{N = 1 0 0}\end{array}$ & $\begin{array}{c}\text { Osteocalcin level } \\
\text { (ng/ml) }\end{array}$ & $\begin{array}{c}\text { P- } \\
\text { value }\end{array}$ \\
\hline $\mathrm{TT}$ & 39 & $10.5 \pm 0.26$ & $\mathrm{P}<0.001$ \\
\hline $\mathrm{Tt}$ & 47 & $13.5 \pm 0.31$ & $\mathrm{P}>0.05$ \\
\hline $\mathrm{tt}$ & 13 & $12.8 \pm 0.27$ & $\mathrm{P}>0.05$ \\
\hline $\mathrm{T}$ & 126 & $10.6 \pm 0.28$ & $\mathrm{P}<0.001$ \\
\hline $\mathrm{t}$ & 74 & $12.5 \pm 0.29$ & $\mathrm{P}>0.05$ \\
\hline $\mathrm{AA}$ & 60 & $14.5 \pm 0.27$ & $\mathrm{P}>0.05$ \\
\hline $\mathrm{Aa}$ & 24 & $12.5 \pm 0.29$ & $\mathrm{P}>0.05$ \\
\hline $\mathrm{aa}$ & 16 & $13.5 \pm 0.26$ & $\mathrm{P}>0.05$ \\
\hline $\mathrm{A}$ & 108 & $12.9 \pm 0.23$ & $\mathrm{P}>0.05$ \\
\hline $\mathrm{a}$ & 92 & $12.7 \pm 0.20$ & $\mathrm{P}>0.05$ \\
\hline
\end{tabular}

*Significant at 0.05 level with non- DM; ** more significant at 0.01 level with non-DM, ***high significant at 0.001 level with non-DM

\section{Discussion}

In this study, mean serum Osteocalcin concentration was significantly and negatively correlated with HbAlc and
FPG in both women and men with obese type 2 diabetes mellitus cases. A number of scientific studies realized that hyperglycemia brings about a reduced bone turnover with osteoblast dysfunction and also suppresses osteocalcin status [12, 13].Some workers had noticed that serum osteocalcin concentration, was lower in females with diabetes after correction for covariance of body weight and serum creatinine $[13,14]$. In addition it proven that mean serum osteocalcin concentration was low prior to therapy and increased after therapy diabetes with medications[15].Previous in vitro research has examined that the activity and expression of alkaline phosphatase (ALT) are increased by chronic hyperglycemia, but reduces cellular calcium uptake and osteocalcin expression [3]; this finding describes the inconsistency in the status of osteocalcin as well as bone alkaline phosphatase (BAP) in medical scientific studies. Results of this particular effort happen to be suitable best with above observations as well as suggest the serum osteocalcin concentration, although not BAP was especially suppressed by hyperglycemia in obese diabetes individuals.

Recently available animal research demonstrated that osteocalcin knockout mice had glucose intolerance and insulin resistance [4], and osteocalcin administration enhanced the derangements by improving the expression of insulin genes and proliferation markers in betapancreatic cells [16]. These information suggest not just that particular hyperglycemia suppresses osteocalcin expression in osteoblast but additionally serum osteocalcin released from osteoblast directly into the blood circulation might modulate pancreatic beta- cell function and also boost glucosemetabolic rate. Nevertheless, this work discovered that had absolutely no correlation between serum osteocalcin level and fasting C-peptide that is a surrogate marker for endogenous insulin secretion. This may be because individuals in these scientific studies received several medications which impact insulin secretion, which includes exogenous insulin and sulfonylurea. Consequently, these works are not able to totally exclude the consequences of the medicines when interpreting the connection between serum osteocalcin levels as well as insulin secretion. Individuals with osteoporosis are known to have an increased incidence of cardiovascular disease [1-5]. Low bone density as well as minimal bone development markers, BAP and osteocalcin, being present in individuals with serious atherosclerosis [17].

The existing analysis demonstrated that serum osteocalcin level was negatively correlated with $\%$ Fat in males with diabetes and was positively correlated with serum complete adiponectin level of females with type 2 diabetes mellitus. These results propose that osteocalcin also is linked with fat metabolic rate of people with diabetes, though there was sex related disparities. Serum complete adiponectin were found to become much higher in postmenopausal females when compared with men [17, 18], and the results displayed this particular sex- related adiponectin variability. The inclusion of osteocalcin to cultured brown and white adipocytes improved adiponectin expression in a dose dependent manner was noticed [19].These information may to some extent

\section{Volume 6 Issue 12, December 2017}




\section{International Journal of Science and Research (IJSR) \\ ISSN (Online): 2319-7064}

Index Copernicus Value (2016): 79.57 | Impact Factor (2015): 6.391

describe the positive correlation between serum levels of total adiponectin and osteocalcin in postmenopausal females. In contrast, absolutely no substantial associations involving osteocalcin and the parameters of atherosclerosis in postmenopausal females were found. These sex related differences may rely on background information such as for instance increased serum adiponectin level as well as a greater percentage of nonsmokers amongst females than males.

In conclusion, this research discovered that serum osteocalcin levels have been linked with total adiponectin levels and glucose, along with fat mass in addition to atherosclerosis parameters in individuals with diabetes. The latest idea which osteocalcin is essential for both bone metabolic process and fat mass and glucose metabolism are supported by these findings.

Polymorphisms in the VDR gene might help the genetic predisposition to specific disease. As vitamin D modulates insulin secretion, it's probable that genetic versions on the VDR gene might help the improvement of type 2 diabetes mellitus. Since individuals with type 2 diabetes mellitus exhibit slight variations in carbohydrate metabolic process long prior to the onset of the disease, genetics factors contributing to its pathogenesis or development may be recognized early in the disease process [19].Data on this effort indicates a significant connection between genotypes of TaqI, with osteocalcin levels.

Nevertheless, earlier scientific studies investigating the association among VDR polymorphisms as well as diabetes risk have developed inconstant results [20]. This particular biochemical evidence might partly explain the results as well as those of a meta- analysis of the same works performed in Asia. This study implies that the TaqI polymorphism is related with susceptibility to obesity in subjects with type 2 diabetes mellitus and diabetic individuals with TT genotype displayed greater BMI and therefore searching for information are agreeable with earlier scientific studies which have discussed the connection between VDR gene genotype TT of TaqI polymorphism and Obesity [21].

Vitamin D induces the secretion of insulin as well as lipoprotein lipase [22, 23]. It's crucial to emphasize that genotypic evaluation reflects an obvious association with BMI and also serum osteocalcin, The TT of TaqI genotype was related to BMI and low levels of osteocalcin in obese subjects. The results are consist with information found by $[21,24]$, which they imply that VDR plays a crucial role in the regulation of lipids, perhaps mediated by the activity of it's within adipocyte calcium metabolic rate; thus, there would an association between bone metabolic process and energy homeostasis. The clinical relevance of the association of the osteocalcin and lipid profile is not completely clear. Osteocalcin metabolic consequences might be partly mediated by a body organ directly involved in insulin secretion, like the pancreas. Nevertheless, an indirect action mediated by the liver and adipose tissue hasn't been.

\section{Conclusions}

In conclusion, the TT genotype of TaqI VDR gene polymorphism was associated with low levels of osteocalcin in obesetype 2 diabetes mellitus.

\section{Competing Interests Statement}

The experts declare that there's absolutely no struggle of interests about the publication of the papers.

\section{References}

[1] Hauschka PV, Lian JB, Cole DE, Gundberg CM. 1989. Osteocalcin and matrix protein: vitamin Kdependent proteins in bone. Physiol Rev 69:990 1047

[2] Price PA .1989. Gla-containing proteins of bone. Connect Tissue Res 21:51-57.

[3] Lee NK, Sowa H, Hinoi E, Ferron M, Ahn JD, Confavreux C, Dacquin R, Mee PJ, McKee MD, Jung DY, Zhang Z, Kim JK, Mauvais-Jarvis F, Ducy P, Karsenty G. 2007. Endocrine regulation of energy metabolism by the skeleton. Cell 130:456 - 469.

[4] Ferron M, Hinoi E, Karsenty G, Ducy P. 2008. Osteocalcin differentially regulates cell and adipocyte gene expression and affects the development of metabolic diseases in wild-type mice. Proc Natl AcadSci USA 105:5266 -5270.

[5] Villafan-Bernal JR, Sanchez-Enriquez S, MunozValle JF. Molecular modulation of osteocalcin and its relevance in diabetes (review).2011. Int J Mol Med. 28(3):283- 93.

[6] Pittas AG, Harris SS, Eliades M, Stark P, DawsonHughes B. 2009.Association between serum osteocalcin and markers of metabolic phenotype. J ClinEndocrinolMetab. 94 (3):827-32.

[7] Vestergaard P. 2011. Risk of newly diagnosed type 2 diabetes is reduced in users of alendronate. Calcif Tissue Int. 2011;89(4):265-70.

[8] Chan DC, Yang RS, Ho CH, Tsai YS, Wang JJ, Tsai KT. 2015.The use of alendronate is associated with a decreased incidence of type 2 diabetes mellitusapopulation based cohort study in taiwan. PLoSOne.10(4):e0123279.

[9] Sierra J, Villagra A, Paredes R et al. 2003. Regulation of the bone-specific osteocalcin gene by p300 requires Runx2/Cbfa1 and the vitamin D3 receptor but not p300 intrinsic histone acetyltransferase activity. MolCelBiol . 23: 3339-3351.

[10] Rosen CJ. 2009.American Society for Bone and Mineral Research. Primer on the metabolic bone diseases and disorders of mineral metabolism, 7th ed. Washington, D.C.: American Society for Bone and Mineral Research.

[11] Maryam Ghodsi, Bagherlarijani, Abbass Ali Keshtkar, EnsiehEsfahani, Sudabeh Alatab4and Mohammad Reza Mohajeri-Tehrani. 2016. Mechanisms involved in altered bone metabolism in diabetes: a narrative review. Journal of Diabetes \& Metabolic Disorders. 15:52. 


\section{International Journal of Science and Research (IJSR) \\ ISSN (Online): 2319-7064 \\ Index Copernicus Value (2016): 79.57 | Impact Factor (2015): 6.391}

[12] Verhaeghe J, Suiker AM, Nyomba BL, Visser WJ, Einhorn TA, DequekerJ, Bouillon R .1989. Bone mineral homeostasis in spontaneously diabetic BB rats.II. Impaired bone turnover and decreased osteocalcin synthesis. Endocrinology 124:573-582.

[13] Gerdhem P, Isaksson A, Akesson K, Obrant KJ. 2005. Increased bone density and decreased bone turnover, but no evident alteration of fracture susceptibility in elderly women with diabetes mellitus. OsteoporosInt 16:1506-1512.

[14] Okazaki R, Totsuka Y, Hamano K, Ajima M, Miura M, Hirota Y, HataK, Fukumoto S, MatsumotoT.1997 .Metabolic improvement of poorly controlled noninsulin-dependent diabetes mellitus decreases bone turnover. J ClinEndocrinolMetab 82:2915-2920.

[15] Botolin S, McCabe LR. 2006. Chronic hyperglycemia modulates osteoblast gene expression through osmotic and non-osmotic pathways. J Cell Biochem 99:411424.

[16] Pennisi P, Signorelli SS, Riccobene S, Celotta G, Di Pino L, La Malfa T, Fiore CE .2004. Low bone density and abnormal bone turnover in individuals with atherosclerosis of peripheral vessels. OsteoporosInt 15:389-395.

[17] Pajvani UB, Hawkins M, Combs TP, Rajala MW, Doebber T, Berger JP, WagnerJA, WuM, Knopps A, XiangAH, UtzschneiderKM, Kahn SE, Olefsky JM, Buchanan TA, Scherer PE. 2004. Complex distribution, not absolute amount of adiponectin, correlates with thiazolidinedione-mediated improvement in insulin sensitivity. $\mathrm{J}$ BiolChem 279:12152-12162.

[18] Waki H, Yamauchi T, Kamon J, Ito Y, Uchida S, Kita S, Hara K, HadaY, Vasseur F, Froguel P, Kimura S, Nagai R, Kadowaki T. 2003. Impaired multimerization of human adiponectin mutants associated with diabetes: molecular structure and multimer formation of adiponectin. $\mathrm{J}$ BiolChem 278:40352-40363.

[19] Palomer X, Gonzalez-Clemente JM, Blanco-Vaca F et al. 2008. Role of vitamin D in the pathogenesis of type 2 diabetes mellitus. DiabObesMetab . 10: 185197.

[20] Li L, Wu B, Liu JY et al.2013. Vitamin D receptor gene polymorphisms and type 2 diabetes: a metaanalysis. Arch Med Research . 44: 235-241.

[21]Dilmec F, Uzer E, Akkafa F et al. 2010.Detection of VDR gene ApaI and TaqI polymorphisms in individuals with type 2 diabetes mellitus using PCRRFLP method in a Turkish population. J Diabetes Complicat. 24:186-191.

[22] Orwoll E, Riddle M, Prince M. 1994. Effects of vitamin D on insulin and glucagon secretion in noninsulin-dependent diabetes mellitus. Am J ClinNutr. 59: 1083-1087.

[23] Querfeld U, Hoffmann MM, Klaus G et al.1999. Antagonistic effects of vitamin D and parathyroid hormone on lipoprotein lipase in cultured adipocytes .J Am SocNephrol. 10: 2158-2164.

[24] Al-AzzawieHF; Al-Darraji SZ, and Al-Kharsani AR.2017. Vitamin D Status and its Receptor Genes BsmI, FokI, ApaI, TaqI Polymorphism in Relation to
Glucose Metabolism in Obese Iraqi Type 2 Diabetes

Mellitus Individuals. J Mol Genet Med. 11:2

Volume 6 Issue 12, December 2017

www.ijsr.net

Licensed Under Creative Commons Attribution CC BY 